\title{
EFFECTS OF METHYLPREDNISOLONE AND GANGLIOSIDE GM-1 ON A SPINAL LESION: A FUNCTIONAL ANALYSIS
}

\author{
Márcio Oliveira Penna Carvalho', Tarcisio Eloy Pessoa de Barros Filho', \\ Marcos Antonio Tebet ${ }^{\mathrm{II}}$
}

doi: $10.1590 / \mathrm{S} 1807-59322008000300015$

Carvalho MOP, Barros Filho TEP, Tebet MA. Effects of methylprednisolone and ganglioside GM-1 on a spinal lesion: a functional analysis. Clinics. 2008;63:375-80.

OBJECTIVES: The pharmacological effects of methylprednisolone (MP) and ganglioside GM-1 on spinal injuries have been thoroughly investigated, but only a few studies have evaluated the interaction between these two drugs.

METHODS: Twenty-four Wistar rats were subjected to contusive injury of the spinal cord produced by the NYU system. These animals were divided into four groups: group I was injected with MP; group II was injected with GM-1; group III was injected with MP together with GM-1; and group control received physiological serum. The animals were evaluated with regard to their recovery of locomotive function by means of the BBB test on the second, seventh and fourteenth days after receiving the contusive injury to the spinal cord. They were sacrificed on the fourteenth day.

RESULTS: This study demonstrated that the MP and GM-1 groups presented functional results that were better than those of the control group, although the enhanced recovery of group II (GM-1) relative to the control group was not statistically significant ( $p>0.05)$. The most notable recovery of locomotive function was observed in the group that received MP alone ( $\mathrm{p}<0.05)$. The group that received MP together with GM-1 presented results that were better than those of the control group ( $\mathrm{p}<0.05$ ).

CONCLUSION: Administration of methylprednisolone alone or with GM-1 was shown to be effective for recovery of locomotive function. Combined administration of these drugs resulted in better outcomes than administration of methylprednisolone alone.

KEYWORDS: Methylprednisolone. Ganglioside GM-1. Spinal cord. Wistar rats. Motor activity.

\section{INTRODUCTION}

Spinal injuries occur at an annual rate of 15 to 40 cases per million people in developed countries. The main causes of spinal cord trauma are motor vehicle accidents, sports, recreational activities, work accidents, gunshot wounds and falls within the home. ${ }^{1}$ Approximately half of the patients who suffer spinal cord trauma present with complete rupture without any preservation of sensory or motor function below the level of the injury. This type of injury is devastating for a patient's quality of life. ${ }^{2}$

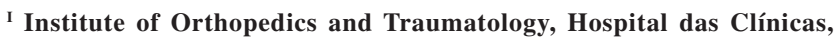
Universidade de São Paulo - São Paulo/SP, Brazil.

"I Orthopedics, Faculdade de Medicina de Jundiaí - Jundiaí/SP, Brazil. marciopennac@uol.com.br

Received for publication on December 14, 2007

Accepted for publication on February 25, 2008
Two distinct events occur during the course of spinal injuries. The first is an acute mechanical trauma that injures and compromises neural elements. The second is the development of secondary lesions caused by progressive ischemia and hypoxia, which trigger further biological events. ${ }^{2}$

Several drugs minimize secondary spinal lesions. These drugs are used to improve the potential for neurological recovery among spinal injury patients. The aim of this therapeutic strategy is to maintain the integrity of the neural elements that did not suffer anatomical injury due to the acute trauma. $^{3}$

Methylprednisolone (MP) has been intensely investigated. Because of its pharmacological properties, it is considered to be neuroprotective. ${ }^{4}$

Monosialoganglioside (GM-1) is a therapeutic alternative for treating lesions of the central nervous system (CNS). A variety of properties have been attributed to GM-1. GM-1 
has been shown to reduce neuronal edema by promoting activation of sodium, potassium and magnesium pumps. Furthermore, it has been shown to facilitate nerve cell homeostasis by re-establishing the membrane equilibrium. ${ }^{5}$ In addition, it has been shown to increase the presence of endogenous neurotrophic factors. These activities diminish the destruction of neurons following trauma by increasing the plasticity of lesioned medullary circuits and hastening the recovery of the functional connections ${ }^{6}$.

Some authors have emphasized the importance of experimental studies that evaluate the results of combined administration of GM-1 and methylprednisolone for the treatment of spinal injuries ${ }^{7}$ since few published studies have this objective. Most of the published papers on this topic are based on clinical evidence and not on experimental studies.

The principal experimental study of this drug combination (MP + GM-1) was published in 1994. This study concluded that combined treatment with these two drugs did not provide any benefit to patients suffering from spinal injuries ${ }^{8}$. Importantly, this result has been questioned by other authors. ${ }^{3,9}$

The New York University (NYU) system ${ }^{10}$ for producing spinal injuries by compression in small-sized animals has been implemented at our Institution. Many centers in various countries have been greatly encouraged to carry out studies on spinal injuries produced by the NYU system, following the international standards of the Multicenter Animal Spinal Cord Injury Study (MASCIS).

The Basso, Beattie and Bresnahan (BBB) locomotor scale $^{11}$ was developed in 1995 to enable evaluation of locomotor recovery patterns among rats subjected to spinal injury using the NYU system. It is important to emphasize that this locomotor function evaluation system has not been applied within our environment until now. Moreover, we have not found any published reports of its use in the investigation of the effects of combined administration of methylprednisolone and GM-1.

The objective of this study was to evaluate the recovery of locomotor function in rats with spinal injuries, which were produced using the NYU system, following treatment with methylprednisolone, GM-1, and methylprednisolone in combination with GM-1, by means of the BBB scale.

\section{MATERIALS AND METHODS}

Twenty-four young male adult Wistar rats of mean weight $327 \mathrm{~g}$ (minimum of $302 \mathrm{~g}$, maximum of $346 \mathrm{~g}$ and standard deviation of $13.5 \mathrm{~g}$ ) were studied. The animals were kept in the microsurgery laboratory in climate-conditioned chambers at a temperature of $25{ }^{\circ} \mathrm{C}$. They were housed in individual cages with light/dark cycles of 12 hours. Food was available ad libitum.

The rats in the experimental group were randomized, identified and divided into four groups of six rats each. All of the rats underwent laminectomy and spinal cord contusion using the NYU system by means of dropping a weight of $10 \mathrm{~g}$ from a height of $25 \mathrm{~mm}$. These groups received the following drugs: group I was injected with MP; group II was injected with GM-1; group III was injected with MP together with GM-1; and group IV (control) was injected with $0.9 \%$ physiological serum.

For the anesthesia procedure, pentobarbital was administered via the intraperitoneal route at a dose of $65 \mathrm{mg} /$ $\mathrm{kg}$. A skin incision of approximately $5 \mathrm{~cm}$ was made along the dorsal medial line. The paravertebral musculature was separated from the spinous processes to expose the vertebral column from T8 to T12. Then, with an appropriate punch, laminectomy was performed in the distal half of $\mathrm{T} 9$ and $\mathrm{T} 10$, without causing injury to the dural sac, thereby allowing enough space to accommodate the impactor head (Figure 1).

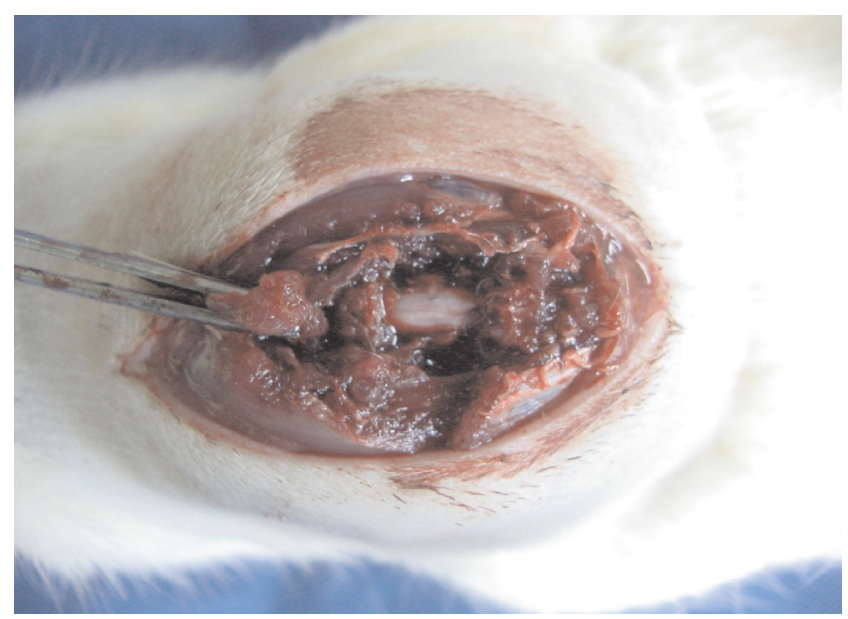

Figure 1 - Exposure of the dura mater following laminectomy

The injury was produced using the NYU system, as developed by Gruner, ${ }^{12}$ in 1992 . (Figure 2).

After receiving the spinal injury, the animal was transferred to a temperature controlled chamber. The animal's rectal temperature was measured 15 minutes after the injury and its bladder was emptied by manual compression at six hours and 24 hours post-injury and then daily until it was sacrificed.

Locomotor function was evaluated by the BBB scale, which was published in 1995, on the second, seventh and fourteenth days after the spinal contusion. Hip, knee and ankle joint movements were observed on the basis of this scale, along with the positions of the trunk, tail and hind paws. From these observations, the animal received a score between 0 and 21 such that 0 indicated total absence of 


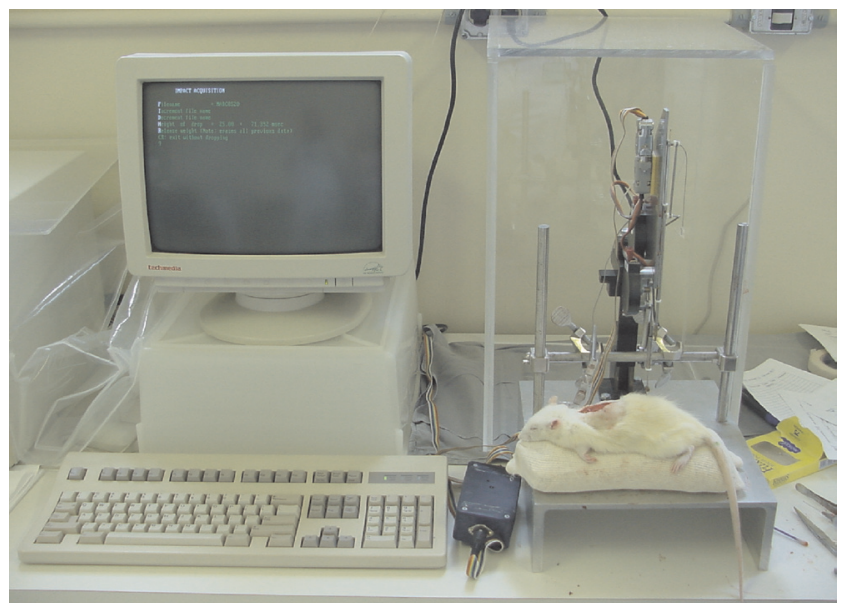

Figure 2 - NYU system

movement and 21 indicated normal movement. Four doctors were trained as observers and formed the study group that evaluated the animals on the BBB scale.

The animals were sacrificed fourteen days after receiving the injury by intraperitoneal application of $140 \mathrm{mg} / \mathrm{kg}$ pentobarbital, in accordance with the rules and regulations of the ethics committee that analyzed the project.

The statistical analyses were both descriptive and comparative. For the quantitative variables (weight and scores on the second, seventh and fourteenth days after the injury), this analysis was done by observing the minimum and maximum values and calculating their means, standard deviations and medians. Absolute and percentage frequencies were also calculated.

Comparative analyses were performed using the Fisher exact test, Kruskal-Wallis nonparametric test, Friedman nonparametric test and Dunn multiple comparisons test. These tests were performed at a significance level of 5\% (p $=0.05$ )

\section{RESULTS}

Table 1 shows the results of the functional evaluation, according to the BBB locomotor scale, for all groups on the second, seventh and fourteenth days after the spinal injury. The means of the values obtained at these three times are shown in Table 2.

Statistical analysis was performed on the comparative results from the BBB test at each time. From the Friedman nonparametric test, groups I, II, III and the control presented significant changes at the times evaluated $(\mathrm{p}<0.01)$. From comparisons in successive pairs, the results from the second day following the spinal injury were significantly different from the results on the fourteenth day for all of the groups $(p<0.05)$. There was no statistical difference in comparisons
Table 1 - Functional evaluations on the second, seventh and fourteenth days following the spinal injury

\begin{tabular}{|c|c|c|c|c|}
\hline & Rat & $2^{\text {nd }}$ day & $7^{\text {th }}$ day & $14^{\text {th }}$ day \\
\hline \multirow{6}{*}{ Group I } & 1 & 0 & 7 & 10 \\
\hline & 2 & 3 & 7 & 12 \\
\hline & 3 & 6 & 8 & 13 \\
\hline & 4 & 3 & 1 & 5 \\
\hline & 5 & 0 & 7 & 12 \\
\hline & 6 & 0 & 6 & 13 \\
\hline \multirow{6}{*}{ Group II } & 1 & 1 & 1 & 8 \\
\hline & 2 & 0 & 1 & 1 \\
\hline & 3 & 0 & 1 & 8 \\
\hline & 4 & 2 & 7 & 12 \\
\hline & 5 & 0 & 8 & 7 \\
\hline & 6 & 0 & 1 & 8 \\
\hline \multirow{6}{*}{ Group III } & 1 & 0 & 8 & 12 \\
\hline & 2 & 1 & 7 & 13 \\
\hline & 3 & 0 & 4 & 8 \\
\hline & 4 & 0 & 6 & 10 \\
\hline & 5 & 0 & 7 & 8 \\
\hline & 6 & 0 & 8 & 10 \\
\hline \multirow{6}{*}{ Control } & 1 & 1 & 2 & 2 \\
\hline & 2 & 0 & 1 & 4 \\
\hline & 3 & 0 & 3 & 3 \\
\hline & 4 & 1 & 1 & 3 \\
\hline & 5 & 0 & 4 & 4 \\
\hline & 6 & 0 & 2 & 2 \\
\hline
\end{tabular}

Table 2 - BBB functional evaluations on the second, seventh and fourteenth days following the spinal injury

\begin{tabular}{lcccc}
\hline Groups & $2^{\text {nd }}$ day & $7^{\text {th }}$ day & $14^{\text {th }}$ day & $\begin{array}{c}\text { Mean for } \\
\text { each group }\end{array}$ \\
\hline Group I & 2.0 & 6.0 & 10.8 & 6.3 \\
Group II & 0.5 & 3.2 & 7.3 & 3.7 \\
Group III & 0.2 & 6.7 & 10.2 & 5.7 \\
Control & 0.3 & 2.2 & 3.0 & 1.8 \\
Mean for each & 0.8 & 4.5 & 7.8 & \\
evaluation day & & & & \\
\hline
\end{tabular}

of the groups between the seventh day following the spinal injury and the other two times (Table 2 and Figure 3).

From the Kruskal-Wallis test, we observed that the groups were statistically different from each other at some of the evaluated times. In the evaluation of the seventh day following the spinal injury, the rats in group III presented significantly better locomotor function than did the control group $(\mathrm{p}<0.05)$. Groups I and III presented a higher mean than that seen in the control group on the fourteenth day following the spinal injury $(\mathrm{p}<0.05)$ (Table 2$)$. 


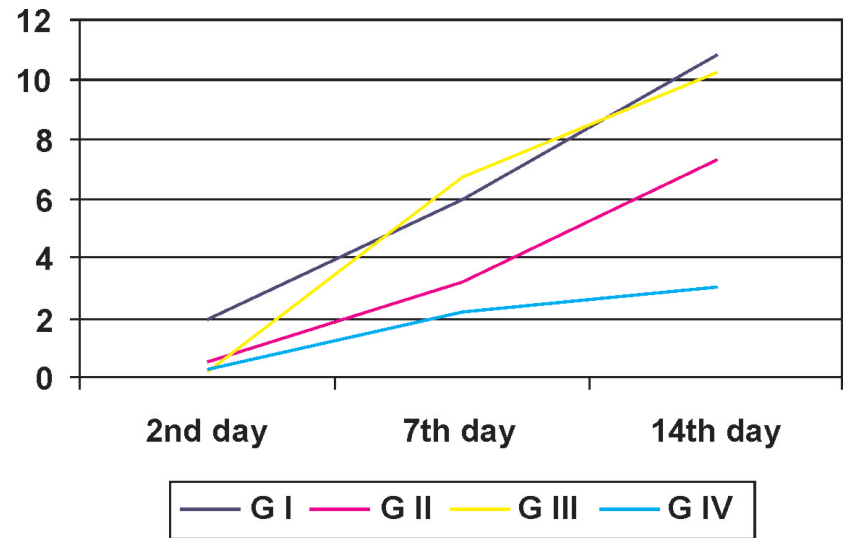

Figure 3 - Evolution of the mean values for functional evaluations, on the second, seventh and fourteenth days after causing the spinal injury, for groups G I, G II, G III and G IV

\section{DISCUSSION}

Several experimental models have been developed to simulate spinal injuries using a weight that freely falls onto animals' spinal cords. ${ }^{13}$ The paper published by Basso, et al, ${ }^{14}$ however, has enabled a great advance in experimental studies on spinal injuries through use of the NYU system.

Experimental evaluations of the efficacy of a drug in the treatment of an animal with a spinal injury require the production of a standardized injury with a locomotor function response that is as similar as possible between multiple animals. ${ }^{14-15}$

Our experiments involved rats, in accordance with the norms of MASCIS. When rats are subjected to spinal cord injuries, they present degrees of locomotor function recovery that may be reproducible. ${ }^{16}$

We chose to use the NYU system because it allows precise monitoring of the height from which the weight falls, the impact velocity and the compression rate for all the animals. This process ensured that we were able to produce calibrated and controlled spinal cord trauma, as demonstrated by Basso et al. ${ }^{14}$

The NYU system can be calibrated such that the fall originates from a rod at a height of $12.5,25$ or $50 \mathrm{~mm}$. We chose the height of $25 \mathrm{~mm}$ because a fall from the height of $50 \mathrm{~mm}$ would cause a complete spinal lesion with high mortality within the first week, while rats with injuries from a weight falling from a height of $12.5 \mathrm{~mm}$ would present almost complete recovery within 10 days. ${ }^{10}$ Several researchers have developed tests to measure locomotor, sensory and reflex functions in animals following spinal contusions ${ }^{17}$. These authors have presented descriptive scales for locomotor performance that have not allowed for precise evaluation of the evolution of the animals' locomotor recovery. ${ }^{11}$

The ideal tool for evaluating locomotor function should be easy to use, sensitive and capable of rapidly showing changes, even among a limited number of experimental animals. ${ }^{14}$ Today, the evaluation method that comes closest to this ideal is the BBB scale, which is a qualitative scale similar to the one originally described by Tarlov ${ }^{11}$.

This model of locomotive assessment (BBB) has been used by several authors ${ }^{18-20}$. As Basso et al ${ }^{11}$ concluded, other authors concur that the BBB tool is a valid and applicable method that can be used to predict and assess the steps of locomotive recuperation, differentiating the behavior outcomes at several time points.

The locomotion measurements proposed in the BBB evaluation scale were reproducible among the examiners trained in our study group. We emphasize that the BBB test must be performed by two trained examiners who have mastered the attributes of the scoring card and the terms on the evaluation scale with a minimum observation time of four minutes for each animal. The examiners must keep the key for this scale at hand, make systematic annotation of the results, re-evaluate the differences found between the results, and repeat the test if necessary. This procedure results in a reduced risk of interpretation error.

In our study, we sacrificed animals on the fourteenth day following the initial spinal injury since the objective was to analyze the effects of functional recovery during the acute phase. The study by Basso et $\mathrm{al},{ }^{11}$ which analyzed the evolution of locomotor function using the BBB method, demonstrated that the animals that underwent spinal contusion using the NYU system presented significant recovery from the fourteenth day after the initial trauma onwards without the use of drugs (score on the BBB scale greater than 10). This was confirmed by a subsequent study by Basso et al. ${ }^{14}$ These authors demonstrated that it was unusual for the animals to exceed a score of six on the BBB scale until two weeks after the injury occurred. We considered this to be an important factor in our study design since any significant improvement in locomotor function within this initial time period might be interpreted as a result of the action of MP with or without concomitant use of GM-1.

From our analysis of locomotor function, we observed a significant improvement in the functional deficit for all of the rats within the same group, as indicated by comparing scores obtained on the second and fourteenth days following the spinal injury. The statistical analysis of the BBB test scores between the second and seventh days showed significant paralysis of the animals' hind limbs, with scores between a minimum of one and a maximum of eight, without any significant difference within the groups or between the groups. These findings suggest that there was an initial transitory stoppage of spine physiological function that was 
more severe than the definitive neurological deficit. This is in agreement with the postulations made by Basso et al. ${ }^{14}$

These observations indicate that a spinal contusion resulting from the NYU system, with a load of $10 \mathrm{~g}$ at a height of $25 \mathrm{~mm}$, is capable of producing an incomplete spinal cord injury in rats. We confirm that locomotor evaluation by the BBB method after the first 48 hours did not reflect the definitive result from the neurological injury. This finding is concordant with the results reported by Constantini ${ }^{8}$ and Basso et al. ${ }^{11,14}$ Most spinal contusions caused in experimental animals are incomplete injuries of the spinal cord, in which at least a band of white substance is preserved. ${ }^{21}$ The potential for recovery depends upon the maximum possible viability of the ascending and descending axons remaining in the white substance and its myelinization. Pharmacological strategies generally focus on controlling the secondary lesion process in the spinal cord (primarily lipid peroxidation) and maintaining the viability of as many of the elements of the white substance as possible. ${ }^{3}$

Although various substances have been used to attenuate the effects of spinal injuries following acute trauma, we chose to utilize methylprednisolone in this study because it provides clinical benefits to subjects with spinal injuries, including improvements in neurological function, as demonstrated in several studies. ${ }^{9,22}$

Yoon et $\mathrm{al}^{23}$ affirmed that the spinal injury model that employs the NYU system presents a very short therapeutic window and that the best results from the use of methylprednisolone are obtained with a dose of $30 \mathrm{mg} /$ $\mathrm{kg}$ applied within the first 30 minutes after the injury. On the basis of that study, we applied a dose of $30 \mathrm{mg} / \mathrm{kg}$ of methylprednisolone in bolus form to the rats (group I) five minutes after the spinal contusion. We repeated this dose three hours later, following the protocol proposed by Constantini and Young. ${ }^{8}$

From our analysis of the results on the BBB scale, we saw that there was a significant difference between group I and the control group, with improvement in the locomotor function of the group I animals. This finding suggests that methylprednisolone may attenuate the effects of the secondary lesion on the spinal cord, resulting in improvement of locomotor function at the cost of anti-inflammatory effects ${ }^{18,24-26}$. These findings conflict with those of Rabchevsky et $\mathrm{al}^{27}$ and Marcon, ${ }^{28}$ who did not observe functional improvements with the use of methylprednisolone.

We used GM-1 in group II because some clinical studies have documented beneficial effects following treatment with GM-1. For instance, GM-1 administration improved the neurological function of patients with spinal cord trauma in the acute and chronic phases. ${ }^{6}$ Other authors have described beneficial effects regarding neurological recovery, which they attributed to an increased axonal dopaminergic effect. This effect was associated with the removal of factors that would inhibit the regeneration of nerve fibers and with the capacity of GM-1 to reduce the retrograde degeneration of axons. ${ }^{29}$ Furthermore, Borzeix et al ${ }^{30}$ observed an increase in blood flow in the injured spinal cord following the application of GM-1.

We did not find any evidence of significant improvement in locomotor function in group II (GM-1) relative to the control group. There may be, however, beneficial effects of long-term treatment since most of the beneficial effects of GM-1 are not observed in the acute phase ${ }^{31}$. We draw attention to the fact that group II performed better than the control group, but without any statistically significant difference. Long-term studies may allow for a more accurate interpretation of the benefit of GM-1 in the treatment of spinal cord lesions.

We co-administered methylprednisolone and GM-1 in group III since some recent experimental studies have drawn attention to the possibility that specific drug cocktails might increase the known beneficial effects of methylprednisolone on spinal cord injuries. Moreover, these studies emphasized that methylprednisolone and GM-1 have been demonstrated to be beneficial in the treatment of patients with spinal cord injuries. ${ }^{32}$

In our analysis of the evolution of locomotor function recovery, we observed improvement in the functional deficit of group III, which suggests that the combined activity of these drugs promotes locomotor recovery among animals that have undergone spinal injury. These results were in disagreement with those found in an experimental study by Constantini and Young ${ }^{8}$. This earlier study concluded that GM-1 blocked the neuroprotective effects of methylprednisolone and that this combination of drugs was worse than their use separately. This conclusion was based upon measured ion volumes. Importantly, they did not evaluate the evolution of the functional recovery pattern among the animals after treatment. We must emphasize that we did not carry out ion volume measurements, so the difference in results between our study and that of Constantini and Young ${ }^{8}$ may result from our use of different methodologies.

Despite the fact that co-administration of methylprednisolone with GM-1 during the acute phase of spinal cord injuries in rats resulted in beneficial functional outcomes, one cannot say that this drug regimen is recommended in humans. All of the studies that have assessed the effects of this drug regimen during the acute phase of injury are experimental studies. Our results indicate that subsequent clinical studies should initiate the use of GM-1 only after the third day following a spinal cord injury. ${ }^{6}$ 


\section{CONCLUSIONS}

1) Methylprednisolone was shown to effectively promote locomotor function recovery. From a comparison between the three treatment groups, the best functional results were obtained when this drug was used alone.
2) The functional recovery among the animals that received GM-1 was superior to that of the control group, although this difference was not statistically significant.

3) The functional recovery of the animals that received methylprednisolone together with GM-1 was superior to that of the control group.

\section{REFERENCES}

1. Sekhon LH, Fehlings MG. Epidemiology, demographics, and pathophysiology of acute spinal cord injury. Spine. 2001;26:2-12.

2. Tator $\mathrm{CH}$, Fehlings MG. Review of secondary injury theory of acute spinal cord trauma with emphasis on vascular mechanisms. J Neurosurg. 1991;75:15-26.

3. Pointillart V, Petitjean ME, Wiart L, Vital JM, Lassié P, Thicoipé M, et al. Pharmacological therapy of spinal cord injury during the acute phase. Spinal Cord. 2000;38:71-6.

4. Hall ED. The neuroprotective pharmacology of methylprednisolone. J Neurosurg. 1992;76:13-22.

5. Walker JB, Harris M. GM-1 ganglioside administration combined with physical therapy restores ambulation in humans with chronic spinal cord injury. Neurosci Lett. 1993;161:174-8.

6. Geisler FH. Coleman WP, Grieco G. Poonian D. The Sygen multicenter acute spinal cord injury study. Spine. 2001;26:87-98.

7. Coleman WP, Benzel D, Cahill DW, Ducker T, Geisler F, Green B, et al. A critical appraisal of the reporting of the National Acute Spinal Cord Injury Studies (I and II) of methylprednisolone in acute spinal cord injury. J Spinal Dis. 2000;13:185-99.

8. Constantini S, Young W. The effects of methylprednisolone and the ganglioside GM1 on acute spinal cord injury in rats. J Neurosurg. 1994;80:97-111.

9. Bracken MB. Pharmacological interventions for acute spinal cord injury. Cochrane Database Syst Rev 2: CD001046, 2000.

10. Rodrigues NR. Padronização da lesão na medula espinhal em ratos wistar [tese]. São Paulo: Faculdade de Medicina da Universidade de São Paulo; 1999.

11. Basso DM, Beattie M S, Bresnahan J C. A sensitive and reliable locomotor rating scale for open field-testing in rats. J Neurotrauma. 1995;12:1-21.

12. Gruner JA. A monitored contusion model of spinal cord injury in the rat. J Neurotrauma. 1992;9:123-6.

13. Behrmann DL, Bresnahan JC, Beattie MS, Shah BR. Spinal cord injury produced by consistent mechanical displacement of the cord in rats: behavioral and histologic analysis. J Neurotrauma. 1992;9:197-217.

14. Basso DM, Beattie MS, Bresnahan JC. Graded histological and locomotor outcomes after spinal cord contusion using the NYU weightdrop device versus transection. Exp Neurol. 1996;139:244-56.

15. Narazaki DK, Barros Filho TEP, Oliveira CRGCM, Cristante AF, Iutaka AS, Marcon RM, et al . Spinal cord regeneration: the action of neurotrophin-3 in spinal cord injury in rats. Clinics. 2006;61:453-60.

16. Metz GAS, Curt A, Meent HV, Klusman I, Schwab ME, Dietz V. Validation of weight-drop contusion model in rats: a comparative study of human spinal cord injury. J Neurotrauma. 2000;17:1-17.

17. Noble LJ, Wrathall JR. Correlative analyses of lesion development and functional status after graded spinal cord contusive injures in the rat. Exp Neurol. 1989;103:34-40.
18. Tebet MA, Barros Filho TEP, Machado IR, Penna de Carvalho MO, Hanania, FR, Daci K. Efeito da metilprednisolona na lesão medular em ratos: análise funcional e histológica. Acta Ortop Bras. 2003;11:80-7.

19. Molina AIS. Análise da sensibilidade e reprodutibilidade da escala de Basso, Beattie e Bresnahan (BBB) em ratos Wistar [dissertação]. São Paulo: Faculdade de Medicina da Universidade de São Paulo; 2006.

20. Carvalho MOP. Estudo da recuperação da função locomotora e histomorfométrico da lesão medular em ratos: efeitos da metilprednisolona e do gangliosídeo G(M1) [dissertação]. São Paulo: Faculdade de Medicina da Universidade de São Paulo; 2007.

21. Basso DM, Bresnahan JC, Beattie MS. Incomplete recovery after spinal cord contusion is associated with a nearly complete loss of vestibulospinal system (VSS) and long descending propriospinal neurons (LDPN) in rats [Abstract]. Soc Neurosci 1993;19:541.

22. Hurlbert RJ. The role steroids in acute spinal cord injury: an evidencebased analysis. Spine. 2001;26:39-46.

23. Yoon DH, Kim YS, Young W. Therapeutic time window for methylprednisolone in spinal cord injured rat. Yonsei Med J. 1999;40:313-20.

24. Taoka Y, Okajima K, Uchiba M, Johno M. Methylprednisolone reduces spinal cord injury in rats without affecting tumor necrosis factor-alpha production. J Neurotrauma. 2001;18:533-43.

25. Merola A, O'Brien MF, Castro BA, Smith DA, Eule JM, Lowe TG, et al. Histologic characterization of acute spinal cord injury treated with intravenous methylprednisolone. J Orthop Trauma. 2002;16:155-61.

26. Lee BH, Lee KH, Yoon DH, Kim UJ, Hwang YS, Park SK, Choi JU, Park YG. Effects of methylprednisolone on the neural conduction of the motor evoked potentials in spinal cord injured rats. J Korean Med Sci. 2005;20:132-8.

27. Rabchevsky AG, Fugaccia I, Sullivan PG, Blades DA, Scheff SW. Efficacy of methylprednisolone therapy for the injured rat spinal cord. J Neurosci Res. 2002;68:7-18.

28. Marcon RM. Estudo experimental da ação da metilprednisolona utilizada antes do traumatismo raquimedular em ratos Wistar [dissertação]. São Paulo: Faculdade de Medicina da Universidade de São Paulo; 2006.

29. Sabel BA, Gottlieb L, Schneider GE. Exogenous GM-1 gangliosides protect against retrograde degeneration following posterior neocortex lesions in developing hamster. Brain Res. 1998;459:373-80.

30. Borzeix MG, Cahn R, Cahn J. Effect of brain gangliosides on early and late consequences of transient incomplete forebrain ischemia in the rat. Pharmacology. 1989;38:167-76.

31. Young W, Flamm ES, Demopoulos HB, Tomasula JJ, Decristo V. Effect of naloxone on posttraumatic ischemia in experimental spinal contusion. J Neurosurg. 1981; 55:209-19.

32. Taoka Y, Okajima K. Role leukocytes in spinal cord injury in rats. J Neurotrauma. 2000;17:19-29. 